\title{
Pagamento por serviços ambientais: instrumento de incentivo à preservação ambiental
}

\section{Josimar Vieira dos Reis}

Secretaria das Cidades do Estado de Pernambuco. Rua Gervásio Pires, 399, Boa Vista, Recife-PE (CEP 50050-070). E-mail: prej86@gmail.com.

Resumo. Os problemas ambientais têm sido a preocupação geral da humanidade com a conservação do meio ambiente é, hodiernamente, uma questão de sobrevivência, de garantir sobrevida às gerações presentes e de possibilitar vida às futuras gerações. O presente trabalho está fundamentada nos principais aspectos sobre o pagamento por serviços ambientais (PSA), que é considerado um mecanismo promissor para resolver alguns problemas relacionados com a degradação dos ecossistemas, principalmente aquelas causadas pela degradação do homem. O pagamento por serviços ambientais ocorre quando beneficiários de uma melhoria da sua qualidade ou quantidade pagam os provedores deste serviço. Estes provedores que adotam práticas conservacionistas ou preservem áreas florestadas. Neste trabalho veremos seus principais aspectos e definições como formas de pagamento, seus desafios e a sua implementação como instrumento econômico, eficácia e eficiência diante do mercado econômico, aspectos sociais e de valor para a proteção dos ecossistemas. A pesquisa é do tipo revisão sistemática de literatura, e buscou informações mais gerais sobre o tema objeto de estudo, para posteriormente envolver um estudo sobre os fundamentos e principais aspectos dos mecanismos sobre o pagamento por serviços ambientais. Conclui-se que se trata de um projeto promissor, com potencial para apresentar equidade, eficácia e eficiência. O que já representa um reconhecimento por sua importância, bem como um avanço para a conservação do meio ambiente. Da mesma forma como as lições depreendidas podem subsidiar a estruturação e a gestão para futuras políticas públicas e projetos de PSA.

Palavras-chave: Pagamentos por serviços ambientais (PSA), Instrumentos econômicos, Políticas públicas.

Abstract. Payment for environmental services: instrument to promote environmental preservation. Environmental problems have been the general concern of humanity to the conservation of the environment is, in our times, a matter of survival, to ensure survival to the present generations and to allow life to future generations. This monograph this based on the key aspects of the payments for environmental services - PSA. Payment for Environmental Services (PES) is considered a promising mechanism to solve some problems related to the degradation of ecosystems, especially those caused by human degradation. PSA occurs when beneficiaries of an improvement in their quality or quantity pay the providers of this service, these providers that adopt conservation practices or preserve

Recebido: 13/07/2015

Aceito: 31/12/2015

Publicado: 31/12/2015

Acesso Aberto

Artigo completo

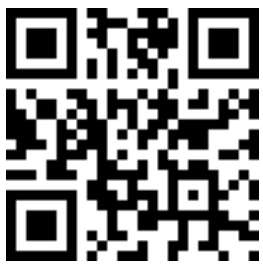


forested areas, This monograph will see its main features and settings as payment methods, his challenges and its implementation as economic instrument, effectiveness and efficiency on the economic market, social aspects and value for the protection of ecosystems. The research is of the systematic literature review, and sought more general information about the subject studied, to further involve a study of the fundamentals and key aspects of the mechanisms of payment for environmental services. We conclude that it is a promising project with the potential to provide equity, effectiveness and efficiency. What is already recognition of its importance, as well as a breakthrough for the conservation of the environment? Just as the inferred lessons can help structuring and public management for future public policies and PES projects.

Keywords: Payments for Environmental Services (PES), Economic instruments, Public policy.

\section{Introdução}

Os problemas ambientais têm sido a preocupação geral da humanidade com a preservação do meio ambiente é, hodiernamente, uma questão de sobrevivência, de garantir sobrevida às gerações presentes e de possibilitar vida às futuras gerações.

Para Spironello (2008) a busca por soluções para as problemáticas ambientais e o início da conscientização da sociedade para a racionalização do uso dos recursos naturais surge ainda na década de 1960 . Paralelamente a esse processo tem origem a ideia de ordenamento territorial cujo principal objetivo era melhorar a qualidade devida da população.

Somente podemos agir irresponsavelmente, quando assumimos responsabilidade [...] o uso que se faz das potencialidades naturais, da água, do solo, da vegetação, somos responsáveis pela sua conservação, mas quando a utilizamos inapropriadamente, estamos sendo irresponsáveis com o que a natureza nos oferece para a nossa existência presente e futura na terra (Santos e Guimarães, 2010).

Há bens, como as matas ciliares, cuja necessidade de preservação é indiscutível, pois significam garantia da vida, da biodiversidade, da qualidade da água potável e da sobrevivência do ser humano, da fauna e da flora. De acordo com a Constituição da República Federativa do Brasil de 1988:
Art. 225. Todos têm direito ao meio ambiente ecologicamente equilibrado, bem de uso comum do povo e essencial à sadia qualidade de vida, impondo-se ao Poder Público e à coletividade o dever de defendê-lo e preservá-lo para os presentes e futuras gerações (Brasil, 1988).

Esta norma constitucional, portanto consagram a preservação do meio ambiente imputando as esferas públicas responsabilidades para assegurar o direito ambiental; descentralizado as competências, entender que se a municipalizando visando à proteção ecológica.

O objetivo deste trabalho é desenvolver o tema relativo à preservação e recuperação do meio ambiente por meio de incentivos financeiros a preservação AMbiental, conjugando uma conduta ativa do Estado e ou da sociedade, consubstanciada num Pagamento por Serviço Ambiental PSA (contrapartida financeira).

Para Gusmão (2005) tem-se o pagamento por serviços ambientais como um forte instrumento na consecução do desenvolvimento sustentável, extensivo ao âmbito global, culminando na inclusão e melhoria do bem-estar dos produtores florestais.

Um tema extremamente atual e instigante em torno do debate sobre o desenvolvimento sustentável refere-se ao PSA, instrumento que remunera ou 
recompensa os produtores protetores das florestas. É uma forma de estimular a conservação, atribuída à exploração sustentável de florestas, contribuindo na reprodução social das populações tradicionais, via distribuição mais equitativa de renda.

Segundo Rojas e Aylward (2003), os serviços ambientais referem-se aos sistemas naturais que oferecem um fluxo contínuo de bens e serviços à sociedade. Os serviços ambientais podem envolver os benefícios hidrológicos, a redução da sedimentação, a prevenção de desastres, a conservação da biodiversidade e o sequestro de carbono.

Os incentivos financeiros fornecidos aos provedores de serviços ambientais estão intimamente relacionados principalmente com o controle dos problemas ambientais. Isso porque a cobertura florestal protege as margens dos corpos hídricos, diminuindo processos danosos ao meio ambiente como assoreamento dos rios, tendo participação direta então na melhoria da quantidade e qualidade da água; além de preservar a fauna e a flora, entre outros subsistemas que envolvem o meio ambiente.

Para Food and Agriculture Organization (FAO, 2004) esquemas de pagamentos por serviços ambientais são mecanismos de compensação flexíveis pelos quais os provedores de serviços ambientais são pagos pelos usuários destes serviços. PSA são considerados mecanismos promissores para o financiamento da proteção e restauração ambiental, assim como forma de complementar e reforçar as regulações existentes.

A maior parte dos esquemas de PSA existentes trabalha com quatro grandes grupos de serviços ambientais: beleza cênica, sequestro de carbono, conservação da biodiversidade e proteção de bacias hidrográficas (Landell-Mills e Porras, 2002).

Desta forma, implantar um programa de remuneração para os serviços ambientais prestados por aqueles que resguardam os cada vez mais restritos fatores ambientais essenciais ao equilíbrio do meio natural é uma estratégia válida que pode propiciar uma "válvula de escape" às intervenções humanas sobre o meio natural, podendo auxiliar nas discussões sobre um efetivo desenvolvimento sustentável.

\section{Base teórica do PSA}

A base teórica de esquemas de pagamentos por serviços ambientais (PSA) não é recente, sendo que os conceitos chaves de externalidades e bens públicos datam pelo menos do início do século XX. No entanto, somente nas últimas décadas PSA vêm ganhando espaço em publicações em todo mundo, assim como têm servido de base para diversas experiências práticas de políticas públicas.

Esquemas de PSA são derivados do Teorema de Coase, de 1960, o qual afirma que através de negociações os agentes internalizam as externalidades e atingem eficiência, independentemente da dotação inicial dos direitos de propriedade e na ausência de custos de transação (Kosoy et al., 2007).

O Teorema de Coase (que na verdade é uma visão/constatação e não um teorema) foi formulado por Ronald Coase (economista norte-americano) e refere que as externalidades ou ineficiências econômicas podem ser, em determinadas circunstâncias, corrigidas e internalizadas pela negociação entre as partes afetadas, sem necessidade de intervenção de uma entidade reguladora. As referidas circunstâncias necessárias para que tal seja possível são, segundo (Coase, 1960) a possibilidade de negociação sem custos de transação e a existência de direitos de propriedade garantidos e bem definidos.

De acordo com Coase (1960) externalidades ocorrem quando uma pessoa age provocando efeitos a outras pessoas, sem o consentimento destas, podendo o efeito ser benéfico - externalidade positiva ou prejudicial - externalidade negativa.

Para Hercowitz e Whately (2008) as externalidades são efeitos secundários gerados em decorrência de uma decisão tomada por um agente econômico individual que afetam outros agentes econômicos que não participam da decisão. As mesmas podem ser positivas ou negativas. 
Assim, por exemplo, suponha que uma indústria utiliza água no seu processo de produção para resfriar as máquinas e devolve a água ao rio em estado diferente do captado, com pior qualidade. Suponhase, ainda, que esta água devolvida ao rio em pior qualidade afetará uma comunidade de agricultores rio abaixo, que verá sua produção comprometida. A indústria, neste caso, está causando uma externalidade negativa que é percebida pela comunidade de agricultores.

\section{PSA no mundo}

Atualmente, a discussão sobre o pagamento por serviços ambientais ainda está sendo delineada nas grandes conferências sobre mudanças climáticas e biodiversidade, no entanto, alguns modelos de PSA já têm sido implementados em algumas partes do mundo.

Poucos programas "maduros" de PSA existem na Ásia, mas aos poucos o interesse pelo tema tem aumentado. O maior número de PSA ou estudos de PSA no continente vem da Indonésia e Filipinas, onde a gestão de bacias hidrográficas tem substituído à abordagem comando e controle (Tres, 2011).

O número total de PSA na América Latina ultrapassa os números na África e na Ásia. Isso se deve à posse da terra rural ser mais segura naquela região, bem como à maior aceitação dos direitos de comercialização do uso da terra e práticas de manejo da terra (Tres, 2011). Na América Latina, há a meta de implementação de 32 fundos até 2015.

A maioria dos países com PSA relacionados a bacias hidrográficas são países em desenvolvimento. Dos desenvolvidos, os únicos apontados são Estados Unidos e França, ambas as referências na questão de políticas ambientais.

Wunder et al. (2008) apontam uma diferença na forma de financiamento dos programas entre os países desenvolvidos e os em desenvolvimento. Aqueles recebem, frequentemente, recursos de vários níveis do governo, enquanto que esses, geralmente, recebem doações. Eles alertam que nos países em desenvolvimento há grande contraste entre os programas públicos e privados, especialmente no tocante à diferenciação dos pagamentos.

Kawaichi (2009) fez um levantamento do uso de políticas ambientais adotadas por diversos países e observou que a maior frequência de uso do mecanismo de PSA ocorre em países em desenvolvimento, apesar de o uso do PSA ser facilitado nos desenvolvidos devido à maior disponibilidade de dados.

Kumar e Chaudhry (2015) estudaram a valoração dos serviços ecossistêmicos da floresta de Arunachal, no Estao de Pradesh, na India.

Apesar de haver mais projetos relacionados à água, os que já estão na fase de implementação são em maior quantidade relacionados ao sequestro de carbono (15 de carbono, oito de água e apenas um de biodiversidade).

\section{Pagamento por Serviços Ambientais no Brasil: alguns exemplos \\ O Brasil, por sua extensão} territorial e presença de grandes remanescentes florestais, além de um crescente aumento na conscientização ambiental possui terreno fértil para a aplicação de PSA's e neste bloco serão discutidas algumas iniciativas brasileiras com o intuito de exemplificar e realizar uma análise dos programas implementos no país a fim de fornecer subsídios para a discussão da temática em implementação de projetos futuros.

Para Wunder et al. (2008) no Brasil, PSA vem sendo discutido com mais atenção desde o lançamento do Programa Proambiente, em 2000, que consistiu em uma experiência inicial de PSA no país, mas demonstrou vários desafios a serem superados.

Entre os exemplos a serem citados estão Proambiente, o ICMS ecológico, o Programa Produtor de Água, iniciativa da Agência Nacional de Águas, a ação do The Nature Conservancy (TNC), o Comitê da Bacia Hidrográfica do Guandu (RJ) e o Projeto Conservador das Águas de Extrema (MG). 
No Estado de Pernambuco já tem seu primeiro projeto de lei do PSA, o projeto Água do Parque, realizado pelo Centro de Pesquisas Ambientais do Nordeste (CEPAN) em parceria com o Instituto Federal de Educação, Ciência e Tecnologia de Pernambuco (IFPE) e a Universidade Federal de Pernambuco (UFPE) chega ao fim comemorando bons resultados. Através de estudos previstos no projeto foi possível identificar que a Companhia Pernambucana de Saneamento (Compesa) economiza entre $\mathrm{R} \$ 9$ mil e $\mathrm{R} \$$ 11 mil em tratamento da água extraída do Parque Estadual Dois Irmãos.

No Brasil existe um projeto de lei que institui a política nacional dos serviços ambientais, o programa federal de pagamento por serviços ambientais, estabelece formas de controle e financiamento desse Programa, conhecido como Projeto de Lei $\mathrm{n}^{\circ}$ 792/2007. A proposta define os conceitos, objetivos e diretrizes da Política Nacional de Pagamento por Serviços Ambientais, além de criar a Comissão Nacional da Política de Pagamento por Serviços Ambientais, o Programa Federal de Pagamento por Serviços Ambientais e o Fundo Federal de Pagamento por Serviços Ambientais.

\section{Tipos de serviços ambientais}

De acordo com Nusdeo (2012) os serviços ambientais são variados, sendo objeto do presente trabalho aqueles de suporte ás condições de vida, que também são muitos e diversificados. Exemplificaram-se estes últimos com a polinização natural, a ciclagem de nutrientes do solo, a manutenção do volume e qualidade dos recursos hídricos e o sequestro de carbono, que permite a estabilização climática.

Os créditos de carbono exemplificam bem a ocorrência simultânea desses elementos, com destaque a um grande impulso dado por intermediários a relação entre os compradores e os prestadores de serviços. Por essa razão, as experiências de remuneração por serviços ambientais atualmente dão-se predominantemente em torno de um grupo de quatro serviços ambientais: conservação da biodiversidade, proteção a bacias hidrográficas, seqüestro e estocagem de carbono e beleza cênica. Às vezes, há possibilidade de fornecimento conjunto de alguns deles.

Dificilmente é observado um serviço ambiental sendo prestado isoladamente, isto quer dizer que as áreas conservadas, por exemplo, fornecem inúmeros serviços interligados entre si, como conservação da biodiversidade, contribuição para a melhoria do corpo hídrico, manutenção da ciclagem de nutrientes, regulação do micro clima, dentre outros (IPEA, 2010). Essa talvez seja uma das limitações do PSA, pois esse instrumento exige que haja um serviço ambiental bem definido sendo prestado. Entretanto, nem sempre é possível haver clara delimitação do serviço.

Wunder e Wertz-Kanounnikoff (2009) citam quatro principais serviços ecossistêmicos utilizados nos pagamentos por serviços ambientais: i) Sequestro de carbono, ii) Proteção da biodiversidade, iii) Proteção de bacias hidrográficas, e iv) Beleza de paisagem.

Inclui-se nesta condição uma grande gama de ecossistemas, desde aqueles relativamente intocados, como florestas naturais, passando por paisagens com diferentes formas de uso humano, até ecossistemas intensivamente manejados e modificados, como áreas agrícolas e urbanas.

\section{Características dos serviços ambientais e formas de pagamentos \\ Os serviços ambientais possuem} características de bens públicos: não exclusividade e não rivalidade. Devido a isso, os direitos de propriedade não são bem definidos (Serroa da Motta, 1998).

$\mathrm{O}$ fato de possuir essas duas características de bens públicos e isso impossibilitarem a formação de preços gera uma falha de mercado que impede a alocação eficiente dos recursos. Como não ocorre o estabelecimento de preços, não há referência quanto à escassez dos recursos, acarretando a tragédia dos comuns. Como consequência disso, surge o problema do 
caronista e há uma super exploração e um subproduto de serviços. Ocorre que quem o "produz" não recebe por isso e quem o “consome” não paga por ele.

De acordo com Sommerville et al. (2009), a compensação do PSA tem o objetivo de ser uma transferência de incentivos positivos, financeiros ou não, cujo impacto proporcione ganho aos provedores de serviços ambientais. Muradian et al. (2010) dizem que o pagamento em dinheiro tem impactos limitados e que, se forem muito pequenos, podem desentusiasmar os provedores, além do que podem diminuir os incentivos éticos à conservação. Se forem prolongados, perdem a característica de incentivo e passam a ser vistos como direito. Há quem diga que recompensas monetárias podem acabar desestruturando um mercado social pré-existente, baseado em laços sociais e reciprocidade. Em situações indesejáveis, os efeitos na conservação são melhores quando não há pagamento do que quando há pagamentos irrisórios.

\section{PSA como instrumento econômico}

De acordo com Loureiro (2008), a um crescente uso de instrumentos econômicos (IEs) para a conservação da biodiversidade, em complemento aos tradicionais instrumentos de comando e controle, é uma tendência mundial.

O PSA é um instrumento econômico baseado no mercado, isto é, é um mecanismo de mercado (IPEA, 2010). Isso significa que ele deve alocar os recursos de forma eficiente, contudo, isso não acarreta necessariamente uma condição sustentável, nem justiça na distribuição dos recursos entre os agentes. Para que essas duas situações ocorram é preciso que haja intervenção governamental na definição da escala a ser adotada no programa, bem como na introdução de regras e instrumentos adicionais que considerem os aspectos distributivos ansiados (IPEA, 2010).

De acordo com Engel et al. (2008), em geral, incentivos econômicos são mais eficientes do que os de pura regulação, os de comando e controle. Isso se deve ao fato de os instrumentos de comando e controle determinarem um mesmo nível de atividade para todos os fornecedores de serviços ambientais, enquanto que os econômicos são mais flexíveis. Por exemplo, o desejo de conservação de florestas seria aplicado a todas as florestas, independente do nível de produtividade dela ou do custo de conservação.

A valoração econômica não é estritamente necessária para se chegar aos valores a serem pagos. No entanto, ela pode ser bastante útil para ajudar a balizá-los. Pelo lado da disposição a pagar, ela pode demonstrar aos compradores uma estimativa dos benefícios econômicos relacionados ao provimento de cada serviço ambiental. Pelo lado dos ofertantes, ela pode ajudar a estimar os custos adicionais incorridos pelos produtores, que dependem dos custos de oportunidade e a diferença de custo da prática sustentável em relação a menos sustentável. Estes custos adicionais freqüentemente balizam a disposição mínima a receber por parte dos produtores para que eles entrem em um esquema de PSA.

\section{Eficácia e Eficiência de PSA e seus aspectos sociais}

Para Wunder et al. (2008) algumas condições são necessárias para o funciona mento dos esquemas de PSA, tais como, as precondições econômica, cultural, institucional e informacional. A precondição econômica se refere à existência de uma externalidade (um benefício externo) que deve ser compensada.

O conceito de Custo de Oportunidade tem especial utilidade para avaliar alternativas quando os bens envolvidos não são comercializáveis, como por exemplo, os serviços de educação, saúde, segurança ou ambientais. Num processo produtivo de bens ou serviços ambientais, os custos de oportunidade de um fator ambiental correspondente ao melhor ganho que se poderia obter utilizando esse fator em vez de outra atividade que não a produção. $O$ custo de oportunidade ambiental é o máximo valor que poderia ter sido obtido pelo usufruto de um recurso ambiental. 
Há vários aspectos que tornam programas de PSA eficientes e efetivos. Dentre eles adicionalidade, não transferência de atividades degradantes, permanência, custos de transação razoáveis, flexibilização dos pagamentos.

A correlação entre esquemas de PSA e equidade é limitada e necessita de atenção especial, uma vez que o foco principal do instrumento é a conservação ambiental. Para atribuir dimensão de justiça e equidade, redução da pobreza ao instrumento, o desenho institucional do programa precisa ser pensado com esse intuito. Muitas vezes, para o lado social ser considerado, o ambiental precisa ser um pouco sacrificado, isto é, reduz-se um pouco o nível de conservação para que determinados atores possam ser incluídos no programa.

Para Antunes (1999), a preservação e sustentabilidade da utilização dos recursos ambientais devem ser encaradas de forma a assegurar a qualidade de vida dos seres humanos que, sem dúvida, necessitam da utilização dos diversos recursos ambientais para a garantia da própria vida, mas sempre de forma racional uma vez que são limitados.

Outro ponto de grande significância que pode ser uma consequência do desenvolvimento dos esquemas de PSA no país é a participação crescente de representantes de produtores rurais em discussões de cunho ambiental, nos quais tradicionalmente os órgãos oficiais de meio ambiente e as ONGs ocupam papel central. $\mathrm{Na}$ medida em que se criam potenciais situações ganha-ganha para todos os atores, na mesma medida cria-se um ambiente mais favorável para estas discussões.

\section{Conclusão}

Conforme visto ao longo do presente trabalho, o pagamento por serviços ambientais apresenta grande potencial de influenciar o comportamento das pessoas e consequentemente, consistem em um instrumento interessante para estimular a conservação e/ou restaurarem suas matas ciliares. Neste sentido, embora não seja o único mecanismo possível de ser utilizado, um programa de pagamento por serviços ambientais se mostra bastante adequado para tal propósito.

Do estudo aqui apresentado, conclui-se, portanto, que programas de PSA são de extrema importância para áreas de alto valor ecológicas ameaçadas e que $o$ mecanismo pode ser interessante na medida em que tem o potencial de revelar e proporcionar maior custo-efetividade ao programa, mas isso vai depender das condições socioeconômicas locais e do seu desenho, tendo em vista tudo o que aqui foi exposto, que os programas de pagamentos por serviços ambientais são considerados precursores de alianças entre o setor público e privado com um objetivo em comum: a conservação ambiental, fato imprescindível ao desenvolvimento econômico atual e futuro.

Por fim, vale mencionar que o mecanismo de pagamentos por serviços ambientais tem o potencial de melhorar seu custo efetividade a media em que passa a ser adotado como ferramenta permanente de conservação e restauração ambiental, e passa a ser realizado com freqüência. Ao longo do tempo, tanto o financiador do programa de PSA, como os proprietários envolvidos, passam a lidar cada vez melhor com o processo, utilizando-se dos aprendizados para otimizar os resultados do programa. Dessa forma, espera-se que a análise da literatura científica sobre o tema PSA aqui apresentadas possam indicar elementos a serem aperfeiçoados para a melhoria de eficiência e equidade em projetos de pagamento por serviços ambientais.

\section{Declaração de conflito de interesses}

Os autores declaram não haver conflitos de interesses.

\section{Referências}

Antunes, P. B. Direito ambiental. 3. ed. Rio de Janeiro: Lumem Júris, 1999.

Brasil. Leis, decretos etc. Constituição da República Federativa do Brasil. Brasília, $1988 . \quad$ Disponível em: 
<http://www.planalto.gov.br/ccivil_03/constitui cao/constituicao.htm>. Acesso em: 03 jan. 2015.

Coase, R. The problem of social cost. Journal of Law and Economics, n. 3, p. 1-44, 1960. Disponível em: <http://www2.econ.iastate.edu/ classes/tsc220/hallam/Coase.pdf $>$. Acesso em: 03 jan. 2015.

Engel, S.; Pagiola, S.; Wunder, S. Designing payments for environmental services in theory and practice: an overview of the issues. Ecological Economics, v. 65, p. 663-674, 2008.

FAO - Food and Agriculture Organization. Payment schemes for environmental services in watersheds. Roma: FAO, 2004. (Land and Water Discussion, Paper 3).

Gusmão, A. V. P. Problemas ambientais globais e a compensação por serviços ambientais como alternativa para a proteção do capital social e ecológico. Revista Jus Navigandi, Teresina, ano 10, n. 589, 2005. Disponível em: <http://jus.com.br/artigos/6341>. Acesso em: 03 jan. 2015.

Hercowitz, M. E; Whately, M. Serviços ambientais: conhecer, valorizar e cuidar: subsídios para a proteção dos mananciais de São Paulo. São Paulo: Instituto Socioambiental, 2008.

IPEA - Instituto de Pesquisa Econômica Aplicada. Sustentabilidade ambiental no Brasil: biodiversidade, economia e bem-estar humano. Brasília: IPEA, 2010. (Série Eixos Estratégicos do Desenvolvimento Brasileiro, Livro 7). Disponível em: <http://www.ipea.gov.br/agencia/images/stories/ PDFs/livros/livros/livro07_sustentabilidadeambi enta.pdf>. Acesso em: 03 jan. 2015.

Kawaichi, V. M. Uma análise das políticas públicas ambientais dos países e a adoção do Pagamento por Serviços Ambientais no Brasil. São Paulo: Universidade de São Paulo, 2009. (Monografia de Graduação).

Kosoy, N.; Martinez-Tuna, M.; Muradian, R.; Martinez-Alier, J. Payments for environmental services in watersheds: insights from a comparative study of three cases in Central America. Ecological Economics, v. 61, n. 2-3, p. 446-455, 2007.

Kumar, S.; Chaudhry, P. Ecosystem services valuation of the forests of Arunachal Pradesh State, India. Brazilian Journal of Biological Sciences, v. 2, n. 4, p. 369-375, 2015. Disponível em: <http://revista.rebibio.net/ v2n4/v02n04a18.html>. Acesso em: 31 dez. 2015.
Landell-Mills, N.; Porras, T. I. Silver bullet or fools' gold? a global review of markets for forest environmental services and their impact on the poor. Hertfordshire, UK: International Institute for Environment and Development, 2002. Disponível em: <https://www.cbd.int/ doc/external/iied/iied-silver-report-2002en.pdf $>$. Acesso em: 02 jan. 2015.

Loureiro, W. ICMS Ecológico, uma experiência brasileira de pagamentos por serviços ambientais. Belo Horizonte: Conservação Internacional, São Paulo: Fundação SOS Mata Atlântica, Curitiba: The Nature Conservancy (TNC), 2008.

Muradian, R.; Corbera, E.; Pascual, U.; Kosoy, N.; May, P. H. Reconciling theory and practice: an alternative conceptual framework for understanding payments for environmental services. Ecological Economics, v. 69, p. 12021208, 2010. Disponível em: <http://www.jatropha.pro/PDF\%20bestanden/re concilingtheory-muradian.pdf $>$. Acesso em: 02 jan. 2015.

Nusdeo, A. M. O. Pagamento por serviços ambientais: sustentabilidade e disciplina jurídica. São Paulo: Atlas, 2012.

Rojas, M.; Aylward, B. Qué estamos aprendiendo de la experiência com los mercados de servicios ambientales en Costa Rica? Revisión y crítica de la literatura. Hertfordshire, UK: International Institute for Environment and Development, 2003. Disponível em: <http://pubs.iied.org/ pdfs/9247SIIED.pdf>. Acesso em 30 nov. 2014.

Santos, A. C.; Guimarães, R. M. A. Estado, democracia e políticas públicas. In: Santos, A. C. (Org.). Filosofia \& Natureza: debates, embates \& conexões. 2. ed. São Cristovão: Editora da UFS, 2010.

Seroa da Motta, R. Manual para valoração econômica de recursos ambientais. Rio de Janeiro: IPEA/MMA/PNUD/CNPq, 1998.

Sommerville, M. M.; Jones, J. P. G.; MilnerGulland, E. J. A revised conceptual framework for payments for environmental services. Ecology and Society, v. 14, n. 2, art. 34, 2009. Disponível em: <http://www.ecologyandsociety. org/vol14/iss2/art34/>. Acesso em: 02 jan. 2015.

Spironello, R. L. Zoneamento antrópicoambiental do Município de Iporã do OesteSC: contribuição para a reflexão e tomada de decisões no âmbito das microbacias hidrográficas. São Paulo: Universidade de São Paulo, 2008. (Tese de Doutorado). 
Tres, D. R. Guia sobre pagamentos por serviços ambientais para proteção de bacias hidrográficas. Joanópolis-SP: Associação Terceira Via, 2011.

Wunder, S.; Engel, S.; Pagiola, S. Taking stock: a comparative analysis of payments for environmental services programs in developed and developing countries. Ecological Economics, v. 65, n. 4, p. 834-852, 2008.

Wunder, S.; Wertz-Kanounnikoff, S. Payment for ecosystems services: a new way of conserving biodiversity in forests. Journal of Sustainable Forestry, v. 28, n. 3, p. 576-596, 2009.

Informação da Licença: Este é um artigo Open Access distribuído sob os termos da Licença Creative Commons Attribution, que permite uso irrestrito, distribuição e reprodução em qualquer meio, desde que a obra original seja devidamente citada. 